\title{
Four-wave mixing in InAIGaAs quantum dots
}

\author{
Leosson, Kristjan; Birkedal, Dan; Hvam, Jørn Märcher
}

Published in:

Summaries of Papers Presented at the Technical Digest Quantum Electronics and Laser Science Conference

Link to article, DOI:

10.1109/QELS.2001.961817

Publication date:

2001

Document Version

Publisher's PDF, also known as Version of record

Link back to DTU Orbit

Citation (APA):

Leosson, K., Birkedal, D., \& Hvam, J. M. (2001). Four-wave mixing in InAIGaAs quantum dots. In Summaries of Papers Presented at the Technical Digest Quantum Electronics and Laser Science Conference (pp. 38-39). Opt. Soc. America. https://doi.org/10.1109/QELS.2001.961817

\section{General rights}

Copyright and moral rights for the publications made accessible in the public portal are retained by the authors and/or other copyright owners and it is a condition of accessing publications that users recognise and abide by the legal requirements associated with these rights.

- Users may download and print one copy of any publication from the public portal for the purpose of private study or research.

- You may not further distribute the material or use it for any profit-making activity or commercial gain

- You may freely distribute the URL identifying the publication in the public portal

If you believe that this document breaches copyright please contact us providing details, and we will remove access to the work immediately and investigate your claim 


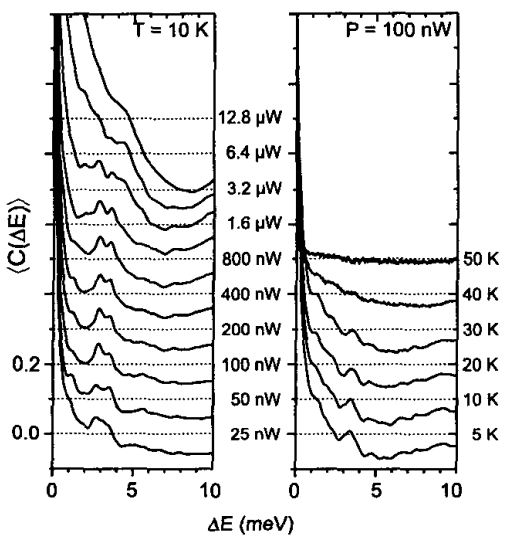

QMJ4 Fig. 2. Left hand side: Averaged autocorrelations $\langle C(\Delta E)\rangle$ at the same sample position with excitation intensity as parameter. The overall shape of the correlation feature remains unchanged over more than two orders of magnitude. Right hand side: Variation of the sample temperature, excitation intensity is constant. The correlation feature vanishes with raising temperature due to the homogeneous broadening of the individual lines. The different averaged autocorrelations are shifted vertically due to clarity. The dotted lines mark the zero line.

have some intermediate separation. They cannot be very close together-due to level repulsionand cannot be too far apart either-due to the finite linewidth.

\section{References}

1. H.F. Hess, E. Betzig, T.D. Harris, L.N. Pfeiffer, K.W. West, "Near-field spectroscopy of the quantum constituents of a luminescent system," Science 264, 1740-1745 (1994).

2. E. Runge, and R. Zimmermann, "Spatially Resolved Spectra, Effective Mobility Edge, and Level Repulsion in Narrow Quantum Wells," Phys. Stat. Sol. B 206, 167-174 (1998).

3. G. von Freymann, E. Kurtz, C. Klingshirn, and M. Wegener, "Statistical analysis of nearfield photoluminescence spectra of single ultrathin layers of CdSe/ZnSe," Appl. Phys. Lett. 77, 394-396 (2000)

4. J.R. Guest, T.H. Stievater, D.G. Steel, D. Gammon, D.S. Katzer, and D. Park, "Nonlinear near-field spectroscopy and microscopy of single excitons in a disordered quantum well," technical digest Quantum electronics and laser science conference QMC2 (2000)

\section{Four-wave mixing in InAlGaAs} quantum dots

K. Leosson, D. Birkedal, J.M. Hvam, Research Center COM, Technical University of Denmark, Bldg.345v, DK-2800 Kgs. Lyngby, Denmark; Email: db@com.dtu.dk

The non-linear optical properties of semiconductor quantum dots are of interest, both fundamentally and for potential device applications. ${ }^{1}$ Large optical non-linearities are predicted due to the three dimensional confinement but the small ac- tive volume of the dots and their large inhomogeneous broadening strongly reduce the interaction with the electromagnetic field. Until now, fourwave mixing (FWM) in III-V quantum dots has only been reported in optical amplifiers at room temperature, where the interaction length is increased by waveguiding in the quantum dot plane. $^{2}$

We have carried out degenerate FWM experiments in a slab geometry on a sample containing 10 layers of $\mathrm{MBE}$-grown $\operatorname{In}_{0.5} \mathrm{Al}_{0.04} \mathrm{Ga}_{0.46}$ As quantum dots (QDs) with $50-\mathrm{nm} \mathrm{Al}{ }_{0.88} \mathrm{Ga}_{0.92}$ As barriers. Ground-state photoluminescence emission from the dots occurs at $1.385 \mathrm{eV}$ with an inhomogeneous broadening (FWHM) close to 80 $\mathrm{meV}$ as shown in Fig. 1 .

The spectrally integrated FWM signals of the QD sample and a GaAs reference sample measured at $5 \mathrm{~K}$ are shown in the inset of Fig. 2. The signals are dominated by strong peaks at $\tau=0$ and at multiples of the pulse roundtrip time through the sample. These strong peaks are due to a twophoton transition to the GaAs substrate material ${ }^{3}$ and is repeated for each reflection of the excitation pulses. However, the FWM signal due to the dots is clearly visible between the sharp peaks and

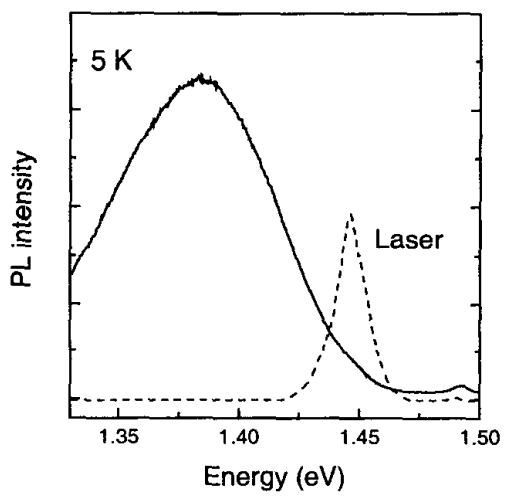

QM55 Fig. 1. Luminescence of quantum dots and laser spectrum used in the FWM experiment. is shown on an expanded scale in Fig. 2. For positive delays, the four-wave mixing signal decays exponentially over more than one order of magnitude with a time constant of about $11 \pm 1 \mathrm{ps}$, corresponding to a dephasing time of $T_{2}=46 \pm$ 4 ps under the assumption of a photon echo. The negative delay signal is caused by FWM due to the reflected probe light and the delayed pump.

The maximum QD FWM signal was observed on the high.energy side of the QD luminescence peak corresponding to the laser spectrum shown as a dashed curve in Fig. 1 . The signal intensity reduces to below our detection limit around the center of the PL peak due to the reduced density of dot states. Similar results were obtained for FWM in CdSe/ZnSe islands. ${ }^{4}$

Using microphotoluminescence spectroscopy on a single-layer sample of similarly prepared quantum dots, we have measured the homogeneous linewidth of photoluminescence lines arising from individual dots with a spectral resolution of $20 \mu \mathrm{eV}$. Fig. 3 shows a Lorentzian fit to four individual PL lines and the statistical distri-

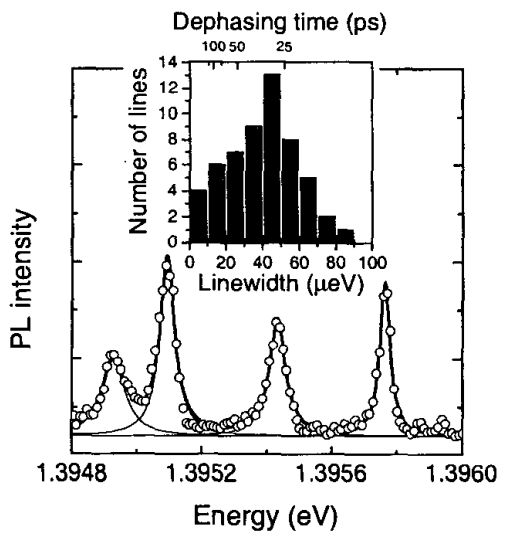

QMJ5 Fig. 3. Micro-photoluminescence spectrum of individual quantum dots. The inset shows the distribution of linewidths for 60 luminescence lines.

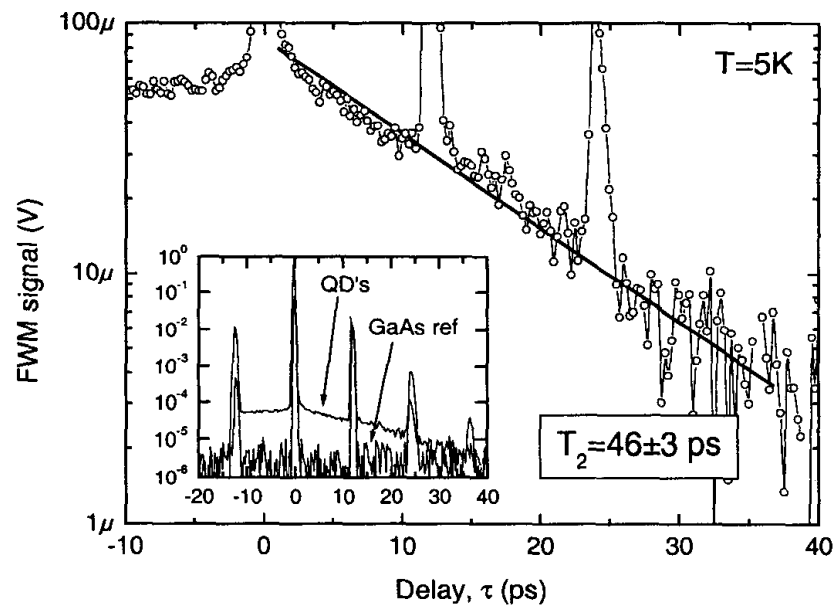

QMJ5 Fig. 2. Four-wave mixing signal from InAlGaAs quantum dots at $5 \mathrm{~K}$. The inset shows comparison to a reference GaAs sample without dots. 
bution of FWHM linewidths of about 60 lines, corrected for the spectrometer response. This distribution of linewidths does not vary with energy across the quantum dot ensemble. The ensemble dephasing time measured in the FWM experiment corresponds to a homogeneous linewidth of $2 h / T_{2}=30 \mu \mathrm{eV}$, which agrees well with a typical single-dot PL linewidth.

We will also discuss the power and temperature dependence of the QD homogeneous linewidth as well as the dependence of detuning of the FWM signal with respect to the QD luminescence peak.

1. Hiroshi Ishikawa, "Applications of Quantum Dot to Optical Devices" in Self-Assembled InGaAs/GaAs Quantum Dots, M. Sugawara, ed. (Academic Press, San Diego, Ca. 1999).

2. P. Borri et al., "Dephasing in InAs/GaAs quantum dots", Phys. Rev. B 60, 7784-7787 (1999); P. Borri et al., "Time-resolved fourwave mixing in InAs/InGaAs quantum-dot amplifiers under electrical injection," Appl. Phys. Lett. 76, 1380-1382 (2000).

3. D. Birkedal et al, "Femtosecond dynamics and absorbance of self-organized InAs quantum dots emitting near $1.3 \mu \mathrm{m}$ at room temperature," Appl. Phys. Lett. 77, 2201-2203 (2000).

4. H.P. Wagner et al., "Exciton dephasing and biexciton binding in CdSe/ZnSe islands," Phys. Rev. B 60, 10640-10643 (1999).

Fig. 1. Sample figure from B. R. Masters, "Threedimensional microscopic tomographic imagings of the cataract in a human lens in vivo," Opt. Express 3, 332 (1998), http:// epubs.osa.org/oearchive/source/6294.htm

\section{QMJ6}

3:00 pm

Over-1.5- $\mu \mathrm{m}$ emissions at room temperature of InAs quantum dots In strained InGaAs quantum well

Jun Tatebayashi, Masao Nishioka and Yasuhiko Arakawa, Research Center for Advanced Science and Technology, and Institute of Industrial Science, University of Tokyo, 7-22-1 Roppongi, Minato-ku, Tokyo, 106-8558, Japan Email: tatebaya@iis.u-tokyo.ac.jp

Since it has been predicted that remarkable improvement of the threshold current density and temperature sensitivity will occur if quantum dots (QDs) are used as the active layer of semiconductor lasers, ${ }^{1}$ several groups have attempted to fabricate quantum dot lasers. Recently, it has been of great interest that QDs will be also available for band structure engineering of semiconductor lasers and many groups have achieved the room temperature lasing at $1.3-\mu \mathrm{m}$ using QDs surrounded with strain-reducing layer as the active layer of laser structure. ${ }^{2-5}$ In this paper, we reported the over-1.5- $\mu \mathrm{m}$ luminescence at room temperature of InAs QDs in strained InGaAs quantum well (QW) grown by metalorganic chemical vapor deposition (MOCVD).

All samples were grown by low-pressure MOCVD using trimethylindium, trimethylgallium, triethylgallium and tertiarybutylarsine. First, we investigated the optical characteristics of InAs QDs capped by GaAs. InAs QDs were grown on $\langle 100\rangle \mathrm{GaAs}$ substrate. The V/III ratio during the growth of InAs QDs was approximately 0.3 and the growth rate was $0.011 \mathrm{ML} / \mathrm{sec}$. The dot density was $2.0 \times 10^{10} / \mathrm{cm}^{2}$ and the mean diameter and height were $25 \mathrm{~nm}$ and $5 \mathrm{~nm}$, respectively. After the formation of InAs QDs, GaAs capping layer was grown. The photoluminescence (PL) of the sample were measured using InGaAs cooledCCD detector. We used a Ti:Sapphire femto-second laser with the peak wavelength of $760 \mathrm{~nm}$ as the excitation source. PL spectrum of InAs quantum dots at room temperature was shown in Fig. 1. The excitation power density was $50 \mathrm{~W} / \mathrm{cm}^{2}$. The emissions from the ground and excited states can be observed at $1347 \mathrm{~nm}, 1248 \mathrm{~nm}$ and 1159 $\mathrm{nm}$, respectively. We also observed the very weak emission from the wetting layer at $937 \mathrm{~nm}$.

Secondly, we studied the PL spectrum of InAs QDs in strained InGaAs QW. After the formation of InAs QDs, a $5 \mathrm{~nm}$ strained InGaAs QW was grown, and capped by GaAs. The cross-sectional scanning tunneling microscope (SEM) image of this sample is shown in Fig. 2(a). The diameter and height of InAs QDs were $20 \mathrm{~nm}$ and $5 \mathrm{~nm}$, respectively. We investigated the PL peak wavelength by changing the indium composition of strained InGaAs QW. The excitation power density was $2.5 \mathrm{~W} / \mathrm{cm}^{2}$. With increasing the indium composition of strained InGaAs QW, the peak wavelength of InAs QDs shifts towards longer values, and we can observe $1.52-\mu \mathrm{m}$ emissions from InAs QDs in $\operatorname{In}_{0.45} \mathrm{Ga}_{0.55}$ As QW (Fig. 2(b)).

In summary, we have successfully observed over- $1.5-\mu \mathrm{m}$ emissions at room temperature of InAs QDs grown by MOCVD. By capping InAs QDs with strained InGaAs QW instead of GaAs, the PL peak wavelength shifts towards longer value, and we have achieved $1.52-\mu \mathrm{m}$ emissions of InAs QDs in $\mathrm{In}_{0.45} \mathrm{Ga}_{0.55} \mathrm{As}$ QW.

\section{Reference}

1. Y. Arakawa and H. Sakaki, "Multidimensional quantum well laser and temperature dependence of its threshold current," Appl. Phys. Lett. 40939 (1982).

2. K. Mukai, Y. Nakata, K. Ohtsubo, M. Sugawara, N. Yokoyama and H. Ishikawa, "1.3 $\mu \mathrm{m}$ CW Lasing of InGaAs-GaAs Quantum Dots at Room Temperature with a Threshold Current of $8 \mathrm{~mA}$, IEEE Photon. Technol. Lett. 111205 (1999)

3. G.T. Liu, A. Stintz, H. Li, K.J. Malloy and L.F. Lester, "Extremely low room-temperature threshold current density diode lasers using

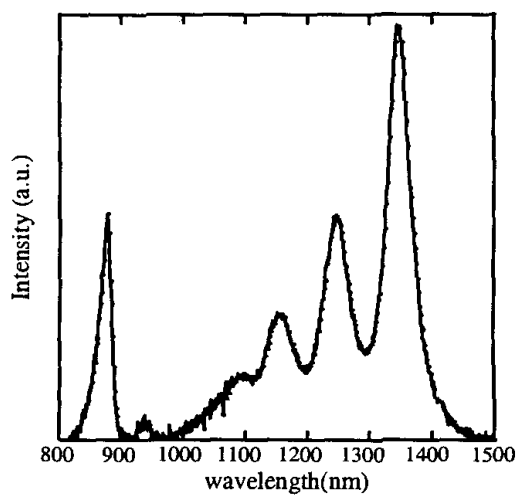

QMJ6 Fig. 1. PL spectrum of InAs QDs capped by GaAs
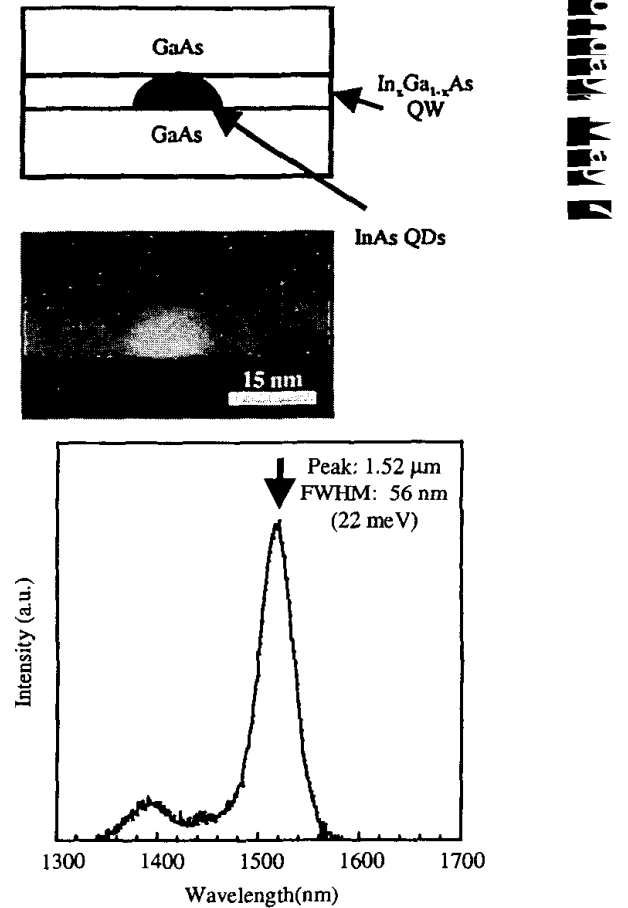

(b)

QMJ6 Fig. 2. (a) Cross-sectional SEM image of InAs QDs in strained InGaAs QW and (b) PL spectrum of InAs QDs in $\operatorname{In}_{0.45} \mathrm{Ga}_{0.55}$ As QW.

InAs dots in $\operatorname{In}_{0.15} \mathrm{Ga}_{0.85}$ As quantum well," Electron. Lett. 351163 (1999).

4. A.E. Zhukov, A.R. Kovsh, N.A. Maleev, S.S. Mikhrin, V.M. Ustinov, A.F. Tsatsul'nikov, M.V. Maximov, B.V. Volovik, D.A. Bedarev, Yu. M. Shernyakov, P.S. Kop'ev, and Zh. I Alferov, N.N. Ledentsov and D. Bimberg, "Long-wavelength lasing from multiply stacked InAs/InGaAs quantum dots on GaAs substrates," Appl. Phys. Lett. 751926 (1999).

5 G. Park, O.B. Shchekin, S. Csutak, D.L. Huffaker, and D.G. Deppe, "Room-temperature continuous-wave operation of a single-layered $1.3 \mu \mathrm{m}$ quantum dot laser," Appl. Phys. Lett. 753267 (1999). 